198 EL TALLER DE LA HISTORIA 2

\title{
JORGE MARIO BETANCUR GÓMEZ, Moscas de todos los colores, historia del barrio Guayaquil de Medellín,
} 1894-1934, Santafé de Bogotá, Ministerio de Cultura, 2000, 482 pp.

\section{GUAYAQUIL, EL BARRIO QUE CONJUGÓ SUS PROPIOS VERBOS}

El Premio Nacional de Historia del Ministerio de Cultura, en su versión de 1998 fue otorgado al libro Moscas de todos los colores, historia del barrio Guayaquil de Medellín, 1894-1934, del investigador antioqueño Jorge Mario Betancur Gómez. Este trabajo se sale del estilo clásico de los estudios de historia del país. Su mismo título es, ya de por sí, provocativo y sugerente, pero más lo es la forma en que está dividido. Los capítulos son verbos en infinitivo que están revelando el carácter de un barrio en constante movimiento y ebullición. Nacer, Civilizar, Gastar, Morir y Amar, sirven de título a cada uno de los capítulos que conforman el libro, y en un estilo ágil y desenfadado muestran la evolución del barrio Guayaquil nacido de la pujanza del Medellín de finales del siglo XIX.

Guayaquil es producto de la iniciativa del acaudalado empresario Don Carlos Coroliano Amador, cartagenero que se fue de la ciudad en la segunda mitad del siglo XIX huyéndole a la crisis, para establecerse en Medellín donde cosechó una gran fortuna y quien mejor supo conjugar los verbos gastar y ostentar, contrario a la cicatería de su coetáneo Pepe Sierra a quien le iba mejor conjugando el verbo atesorar. Amador "supo que el pequeño poblado estaba en trance de parir una ciudad, como las que él visitaba, hasta por siete meses, en cada viaje a Europa. Hizo cuentas y trazó planes para sacar buena ventaja de los nuevos tiempos. Vio el 
mercado estrecho, desordenado, sucio, antihigiénico y caótico del parque de Berrio, en el centro, y pensó en sus mangas y pantanos de Guayaquil. Una estupenda oportunidad para valorizar su tierra y, de paso, realizar una 'obra civica' por Medellín (p. 34).

El 23 de junio de 1894, con toda la pompa y la solemnidad de los actos oficiales, con sacerdote y misa, y con las palabras progreso y moderno repitiéndose en los discursos, la ciudad acudió a la inauguración del mercado público en el barrio Guayaquil. Sus instalaciones se erigían como el más grande edificio del siglo XIX en la ciudad de Medellín. Al fondo, ocho calles dispuestas para el nuevo barrio comercial que presagiaban un próspero futuro con la construcción de una terminal de la línea férrea.

Paradójicamente, las locomotoras del progreso traían también la miseria; aunque en segunda clase, ella también viajaba en tren. "Como negociantes, los Amador, los Santamaría, los Vásquez y los Restrepo no fallaron en sus cálculos cuando invirtieron a finales del siglo XIX, en la compra de algunos terrenos del barrio Guayaquil por donde llegaría el ferrocarril. Tampoco se equivocaron cuando edificaron las mejores casas de la ciudad en calles del barrio, como la pintoresca de La Alambra. Pero no previeron que el tren traería a miles de extraños que se enamorarían del aristocrático barrio planeado por ellos y lo convertirían en un sector de vida popular, un sitio de gentuza vulgar" (p.113). De manera que el barrio donde se ubicó lo más granado de la élite antioqueña sería también el espacio de las "moscas de todos los colores", forasteros sin fortuna que buscaban una oportunidad en la gran urbe. Prostitutas, mendigos, vagos, emboladores, borrachos, delincuentes, buscapleitos de oficio, cuchilleros... se fueron acomodando en casuchas de piezas húmedas y estrechas, creando un espacio abigarrado de emociones.

Aparte de comerciar, ganar, atesorar, Guayaquil empezó a conjugar nuevos verbos. Fingir, robar, asaltar, timar, jugar, beber, reñir, cortar, disparar, matar, pecar, mendigar, prostituir, desobedecer, cagar... Eran los verbos conjugados por los advenedizos, quienes crearon un mundo alterno, con subsistencia y vida propia. A 


\section{EL TALLER DE LA HISTORIA 2}

estos nuevos actores la ciudad los relegó a la condición de parias, los convirtió en lo "otro"; testimonio de la barbarie, el mal y la perdición; ejemplo vivo, cotidiano y cercano para los sermones de obispos y moralistas que veían en el nuevo barrio la encamación de todos los vicios que ponían en peligro el mito de la pujante raza paisa.

Volviendo al autor Jorge Mario Betancur Gómez estudió periodismo en la Universidad de Antioquia e Historia en la Universidad Nacional de Medellín. Ha trabajado en varios documentales y programas de televisión y ganó el premio India Catalina en el Festival de Cine de Cartagena con la serie Muchachos a lo bien, en 1997. La influencia del periodismo es evidente en su estilo de escritura. La prosa suelta, ágil y amena de su obra, nos muestra una extensa crónica, y representa un duro golpe a la perniciosa costumbre de citar los datos y encajarlos, a como dé lugar, en citas teóricas. Acto de pedantería académica que termina por sacrificar la buena escritura necesaria en cualquier texto, ya sea de economía, esoterismo o historia.

Este olfato periodístico - asertivo en cuanto a estilo y lenguaje-, también lo lleva a concentrar su atención sobre los hechos más llamativos y extraordinarios. Por estar cimentado en crónicas y editoriales de prensa, sermones, fuentes policiales y de denuncias, el trabajo de Betancur construye la imagen de un barrio sórdido y escabroso, una crónica roja con pasajes en los que el lector puede salir salpicado de sangre. Al tema que trata sobre los asesinatos con armas blancas, es al que más páginas le dedica (pp. 293-328). Guayaquil parece ser sólo el escenario de prostitutas, hampones, vagos, borrachos y mendigos. La pobreza y la humildad tienen sentido sólo a partir del ilícito.

Esta visión nos remite a tres problemas. En primer lugar, hay implícita una idea de lo popular asociada sólo al desorden y a los actos delincuenciales, lo que indudablemente nos acerca aúna concepción demasiado sesgada y homogénea de la cultura popular, que evidencia una negación de los conflictos y las contradicciones en su interior, como lo han criticado los importantes trabajos de 
E.P. Thompson, Peter Burke y Mijail Bajtin. Hubiese sido interesante por ejemplo explorar las dinámicas de diferenciación (trabajo, educación, etc.) que algunos sectores de Guayaquil intentaron desarrollar ante la avalancha de críticas y comentarios negativos. Dentro de esas "moscas de todos los colores" debía de haber grupos que, a pesar de la pertenencia socio-espacial, compartían otros imaginarios.

En segundo lugar, podríamos decir que el autor es presa de los mismos juicios que la élite y el clero hacen de Guayaquil, y por abusar de ellos como fuentes, termina construyendo la misma imagen del barrio. Una concepción carnavalesca de lo popular posibilita la creación de una visión que no dista mucho de la idea del buen salvaje, tan presente en la literatura antropológica del siglo XIX y de buena parte del XX, en donde la cultura popular aparece, no como un componente activo, sino como un componente exótico.

Por último, en ese afán de mostrar a Guayaquil como un barrio excepcional (no negamos que lo fue) se pierde la contextualización del sector en dinámicas de la ciudad. El barrio termina convirtiéndose en un microcosmos en cierta forma desligado del ritmo del resto de la ciudad. Si bien el barrio aprendió a conjugar sus propios verbos y creó una fuerte y avasallante identidad, desligarlo del escenario local es dejar de enriquecer una obra que, pese a todo, es sumamente interesante.

Javier Ortiz Cassiani

Programa de Historia Universidad de Cartagena 